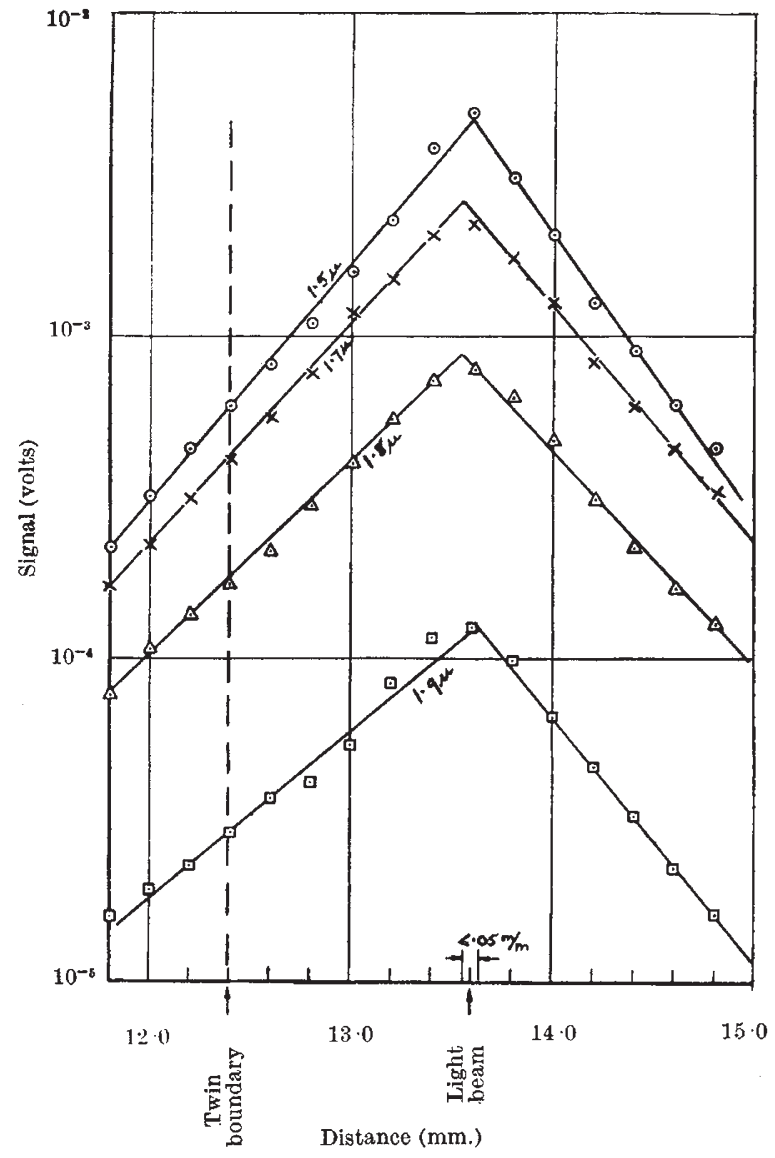

The diffusion distances derived from these measurements are given below, together with the corresponding life-times, calculated on the assumption of $43 \mathrm{~cm}^{2}$ sec. $^{-1}$ for the diffusion coefficient of holes. The somewhat lower value for $1.5 \mu$ is presumably due to the increased absorption of the radiation near the surface layer and the correspondingly higher rate of recombination there.

\begin{tabular}{|c|c|c|c|c|}
\hline $\begin{array}{l}\text { Wave-length }(\mu) \\
\text { Diffusion distance (mm.) } \\
\text { Life-time ( } \mu \text { sec.) }\end{array}$ & $\begin{array}{l}1 \cdot 5 \\
0 \cdot 54 \\
68\end{array}$ & $\begin{array}{l}1 \cdot 7 \\
0.63 \\
92\end{array}$ & $\begin{array}{l}1 \cdot 8 \\
0.65 \\
98\end{array}$ & $\begin{array}{l}1 \cdot 9 \\
0.66 \\
102\end{array}$ \\
\hline
\end{tabular}

As a further check on the transmission of holes across a twin boundary, transistor action was investigated on another similar crystal with an emitter point on one side of the twin boundary and a collector on the other. The two points were spaced about $0.2 \mathrm{~mm}$. from either side of the boundary. Distinct transistor action was observed as readily as on any similar piece of single-crystal material.

It would therefore appear that, in contradistinction to grain boundaries, twin boundaries will not impede the transmission of free electrons or holes to any marked degree. This is not surprising, as the transmission from one twin to the other takes place across a single atomic layer ; also, the energy involved in twinning is quite negligible compared with the main lattice energy. Electrons and holes can obviously bridge such a narrow region by the wave mechanical tunnel effect without any marked resistance.

It is suggested that similar techniques might, with advantage, be applied to the study of various faults in the structure of solids, as, for example, to the boundary region between two grains which have been made to grow with certain specified orientations.

E. BILLIG

M. S. RIDOUT

Research Laboratory,

Associated Electrical Industries, Ltd., Aldermaston Court,

Aldermaston, Berkshire. Dec. 3.

1 Haynes, J. R., and Shockley, W., Phys. Rev., 75, 691 (1949).

${ }^{2}$ Haynes, J. R., and Shockley, W., Phys. Rev., 81, 835 (1951).

\section{Fatigue Strength of Pure Tin at Room Temperature}

THE fatigue strengths of many tin alloys at both room and elevated temperatures have been reported ${ }^{1}$, but I have found no figure for pure tin in the literature. Experiments have therefore been made to determine the fatigue strength of the pure metal in the cast condition. The measurements were made on $\mathbf{a}$ Wöhler type machine with four-point loading, using a relatively thick specimen with a short gauge-length.

Tests were made up to $10^{8}$ cycles of stress and these showed no evidence of a true fatigue limit. The fatigue strengths at $10^{7}$ and $10^{8}$ cycles of stress are 0.19 and 0.17 ton per square inch respectively.

It is of interest that the fractures produced by fatigue were wholly intercrystalline. After testing, the grain boundaries were revealed on the polished surface of the specimen, indicating that intergranular movement had taken place during the test. In addition, a general roughening of some grains indicated that transcrystalline deformation occurred at the same time, either on sub-boundaries or on slip planes.

E. C. Ellwood

R. DUCKETT

Tin Research Institute,

Fraser Road, Perivale,

Greenford, Middlesex. Nov. 17.

1 Macnaughton, D. J., J. Inst. Metals, 55, 33 (1934), von Göler, K., P. G., Greenfield, L. T., and Duckett, R., Metallurgia, 36, 113.

\section{Graphite Lubrication in Grey Cast Iron}

DuRING work with the Lunn apparatus ${ }^{1}$ on dry friction between a sliding tungsten carbide ball and a grey cast iron test-piece, two different types of tracks were obtained. The first type of track had a black appearance when examined with the naked eye or in the microscope, and a continuous film of deformed graphite covered the surface of the track. The $L^{r}$ value of this film was high, which indicated good electric conductivity of the film. The second type of track had a bright, metallic appearance, and on examination with the microscope very small amounts of deformed graphite were observed. In this case, the $L$ value was low, which indicated the build-up of an insulating film-even if the specific pressure is of the magnitude of $10,000-12,000 \mathrm{lb}$./sq. in.

The two types of tracks could be produced on the same test-piece, depending on the conditions under which the experiment was carried out. If conditions did not allow water vapour to be adsorbed to the cast iron surface, the first type of track was obtained. Adsorption of water vapour always resulted in a change to the second type of track. 